\title{
A new model for predicting fluid loss in fracture-porosity reservoir
}

\author{
Jinjiang Liu*, Fuxing Zhang, Peng Qian, and Wenlin Wu \\ Drilling and Production Technology Research Institute, PetroChina, Liaohe Oilfield Company, No. 91, Huibin street, \\ Panjin, Liaoning Province 124010, PR China
}

Received: 20 October 2020 / Accepted: 10 March 2021

\begin{abstract}
Drilling fluid loss always occurs in fracture-porosity reservoirs and it causes severe problems. To reduce and prevent lost circulation, it is important to get to know the cause and the characteristic of drilling fluid loss. According to the approach in the reservoir simulation and well test analysis, a new model for drilling fluid loss in fracture-porosity reservoir is presented. Multi fractures in the formation and drilling fluid seepage between fracture and rock matrix have been considered in the model. The governing equations are derived based on the principle of conservation of mass. The model is solved numerically using Newton-Raphson iterative method. The obtained results indicate that drilling fluid leak-off has great influence on the total leakage volume. It is necessary to consider the impact of the drilling fluid leak-off. In addition, influence of formation properties, such as fracture stiffness, rock matrix porosity, rock matrix permeability, and operation factors, such as pressure difference between wellbore and formation, are also analysed in detail in the paper which could help better understand the factors that influence the drilling fluid loss during drilling operation.
\end{abstract}

\section{Introduction}

Drilling fluid loss is a kind of phenomenon that drilling fluid leaks into formations during drilling operation and well completion. It is one of the major problems encountered in naturally fractured reservoirs. It not only extends the drilling period and causes economic loss, but also causes some severe accidents, such as wellbore collapse and blowout. According to the statistic in the oil field, expense for preventing and controlling lost circulation takes large proportion of total operation cost $[1,2]$, so it is significant to solve the problem of drilling fluid loss.

Recognizing the mechanism of the drilling fluid loss is the premise of plugging. A few studies have been published about the mechanism of this phenomenon. Lietard et al. [3] presented a model about the leakage of Bingham fluid in a finite radical fracture. Pressure difference between wellbore and formation was considered constant. The relationship between dimensionless time and dimensionless leakage was expressed by figures, so engineers on the field could predict the fracture width based on the leakage rate. Sanfillippo et al. [4] presented a model about the leakage of Newtonian fluid in a finite radical fracture. In their model, fracture was regarded as non-deformable and fracture width was constant. As rheology of drilling fluid had a great influence, choosing Newtonian fluid made model limited. Verga et al. [5] measured the drilling fluid leakage data of three

\footnotetext{
* Corresponding author: liujinj@126.com
}

wells. Inversion analysis was conducted based on the previous models and results were discussed with respect to imaging log data, core analyses, and well test interpretation results. Lavrov and Tronvoll [6] presented a leakage model of Newtonian fluid, in which linear deformation of fracture and fracture surface filtration were taken into account. In the next year, based on the previous model, Lavrov and Tronvoll [7] presented a leakage model considering drilling fluid as power-law fluid. Influences of formation properties and engineering factors on the leakage were analyzed. Tempone and Lavrov [8] used discrete element method to simulate the lost circulation. The research showed that the loss rate was mainly influenced by the fracture grid shape and cumulative loss was mainly influenced by the fracture length and fracture stiffness. Majidi et al. $[9,10]$ assumed that the fracture wall deformation was described by a linear aperture-pressure deformation law. They concluded that the fluid loss in the fractures could be stopped either because of high yield stress of drilling fluid or limited extension of the fracture. Ozdemirtas et al. [11] developed a new model which considered a rough, planar, horizontal, square-shaped fracture. In their study, drilling fluid was considered as Newtonian fluid and the fracture wall deformation was described by a linear aperture-pressure deformation law. The model was solved numerically. The result showed that the roughness had great influence on the leakage rate. Li et al. [12] developed a new model which considered a rough, planar, oblique, square-shaped fracture. In their model, fracture was assumed following the linear 
fracture deformation law and drilling fluid was considered as Bingham-Plastic fluid. The effects of different parameters, such as consistency factor, fracture roughness, fracture angel, on the drilling fluid loss rate and the amount of the drilling fluid loss were analyzed. Razavi et al. [13] presented a model to simulate the drilling fluid loss into natural fracture. The result indicated that the effect of leak-off may significantly increase the drilling fluid loss rate. Wang et al. [14] developed a model that could predict the pre-spud drilling fluid loss rate based on the finite element analysis. Xia et al. $[15,16]$ developed a two-scale model to simulate drilling fluid loss in fractured formation. Two different flow models were used to describe the flow in matrix and fracture.

The exiting researches mainly focused on the drilling fluid loss in single fracture, in which formation was regarded as impermeable. However, in reality, fractures develop complexly in the formation. It is not accurate in considering only one fracture. On the other hand, properties of rock matrix have great influence on the drilling fluid loss rate. For example, when pressure in the fracture is larger than the formation pressure, drilling fluid will seepage into the rock matrix and cause the decrease of pressure in the fracture. It is not conformable with the actual situation and will make error if permeability of rock matrix is ignored.

In this study, based on the dual-media model, a threedimensional drilling fluid loss model is developed, in which multi-fractures and seepage between fracture and rock matrix are considered in the model. A deformable nonpropagating rectangle fracture with permeable wall is considered. Power-law fluid is considered for formation and drilling fluids. Fracture surface is assumed smooth. The numerical model was solved by the full implicit finite difference technique. In addition, some parameters associated with the physical properties of fracture and matrix, such as fracture aperture, matrix permeability, fracture density, etc., were analyzed.

\section{Geological model}

Fracture-porosity reservoir is a common kind of reservoir in carbonate rock. In this kind of reservoir, oil and gas can flow and be stored in both fractures and rock matrices. In general, reservoir spaces occupied by fractures are much smaller than that occupied by pores of rock matrices, so fracture porosity is much smaller than rock matrix porosity. On the other hand, oil flow capacity of fractures is much larger than that of rock matrices, so fracture permeability is larger than rock matrix permeability. Fracture morphology in the reservoir is random and it is difficult to predict the distribution of fractures in the formation precisely. In order to facilitate the research, Warren-Root model [17] is adopted to simplify the reservoir model (Fig. 1). According to the Warren-Root model, the rock matrix blocks are cut by orthogonal fractures. Drilling fluid can flow both in the fracture and rock matrix. The initial fractures widths are assumed to be equal.

\section{Development of model}

\subsection{Basic assumptions}

The reservoir is a rectangular reservoir. There are several rectangular fractures in the horizontal direction and vertical direction, which divide the formation into several blocks. The formation is assumed to be horizontal, which means the influence of formation dip angle is neglected. Fractures are orthogonal. Initial apertures of fractures are constant and the fractures surfaces are smooth (Fig. 2). At the beginning, pressure in the fracture and formation pressure are assumed to be equal.

Formation fluid and drilling fluid are assumed to have the same rheological properties. There are no physical reaction and chemical reaction between formation fluid and drilling fluid. Drilling fluid flows in laminar state in the fracture and flows through fracture wall into rock matrix by seepage.

The well is a vertical well and it is in the centre of the formation. When $t=0$, drilling fluid begins to leak into formation through the fracture and rock matrix.

\subsection{Fracture deformation equation}

When drilling fluid loss happens, drilling fluid flows into formation through fractures and the increase of pressure in the fracture leads to the change of fracture aperture and permeability of fracture. So it is important to calculate the fracture width accurately. At the moment, there are two kinds of fracture deformation model: linear deformation model and exponential deformation model [18, 19].

In the linear deformation model, fracture aperture at a given point is assumed to be a linear function of the pressure difference between formation pressure and pressure in the fracture. In the exponential deformation model, fracture aperture at a given point is assumed to be an exponential function of the pressure difference between formation pressure and fracture pressure.

In this work, linear deformation model is chosen to describe the deformation of fracture. Linear deformation model can be expressed as:

$$
w=w_{0}+\frac{\Delta P}{k_{n}},
$$

where $\Delta P$ is the pressure difference between fracture pressure and formation pressure, $\mathrm{MPa} ; k_{n}$ is the stiffness coefficient, $\mathrm{Pa} / \mathrm{m} ; w_{0}$ is the initial fracture width, $\mathrm{mm}$; $w$ is the fracture width, mm.

The initial fracture aperture $w_{0}$ is assumed to be nonzero, which means the fractures remain open under the formation pressure.

\subsection{Fluid rheology}

Power-law model is widely used in the hydraulic calculation of drilling fluid, as it matches the actual property of drilling fluid. In this study, power-law model is chosen to describe the fluid rheology. Both drilling fluid and formation fluid 

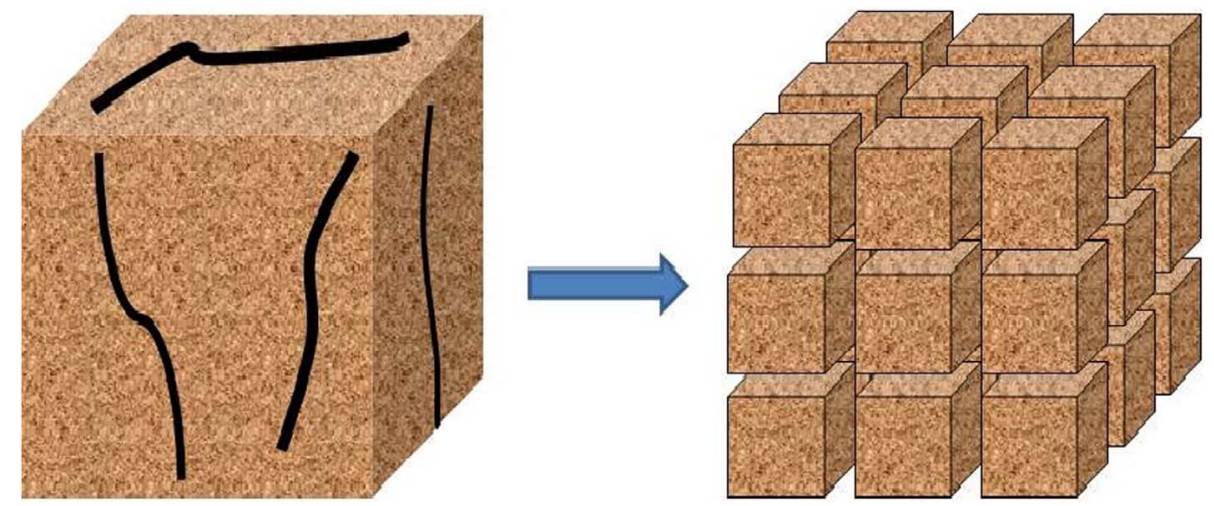

Fig. 1. The schematic of the dual-media reservoir model.

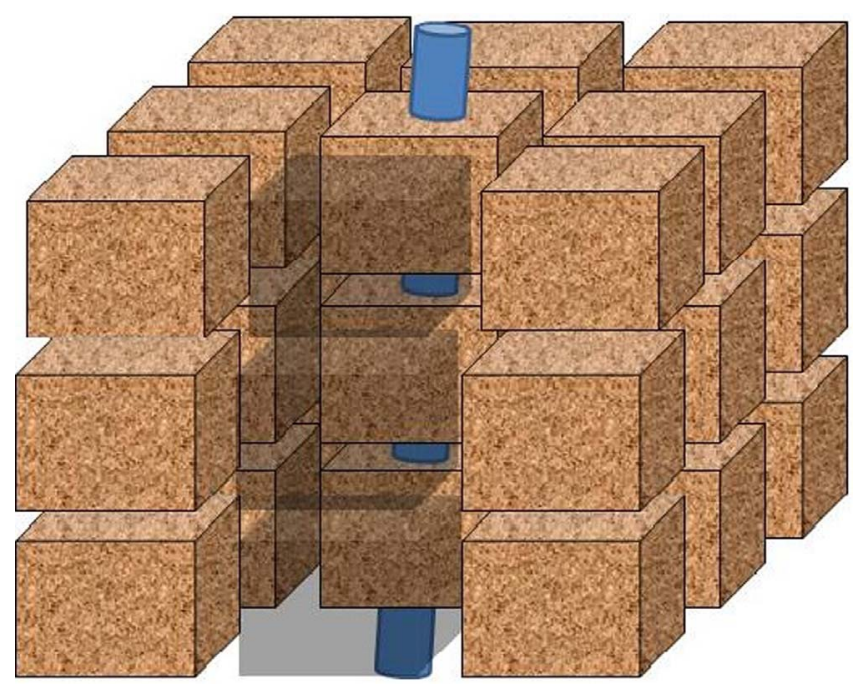

Fig. 2. The schematic of the orthogonal fracture.

conform to the power-law rheology. The model can be expressed as follows [20, 21]:

$$
\tau=K \gamma^{n}
$$

where $\tau$ is the shear stress, $\mathrm{Pa} ; \gamma$ is the shear rate, $\mathrm{s}^{-1} ; K$ is the consistence factor, $\mathrm{Pa} \mathrm{s}^{n} ; n$ is the flow behavior index.

\subsection{Continuity equation}

Fluid flow in fracture-porosity reservoirs can be divided into two parts based on the flow states of drilling fluid: laminar flow in the fracture and seepage flow in the rock matrix (Fig. 3). Using conservation of mass in Cartesian coordinate, incompressible fluid flows in fracture and rock matrix can be expressed separately as follows [22, 23]:

In the fracture system:

$$
\frac{\partial}{\partial t}\left(\emptyset_{\mathrm{f}} \rho\right)+\operatorname{div}\left(\rho v_{\mathrm{f}}\right)-q_{\mathrm{f}}=0 .
$$

In the rock matrix system:

$$
\frac{\partial}{\partial t}\left(\emptyset_{\mathrm{m}} \rho\right)+\operatorname{div}\left(\rho v_{\mathrm{m}}\right)-q_{\mathrm{m}}=0
$$

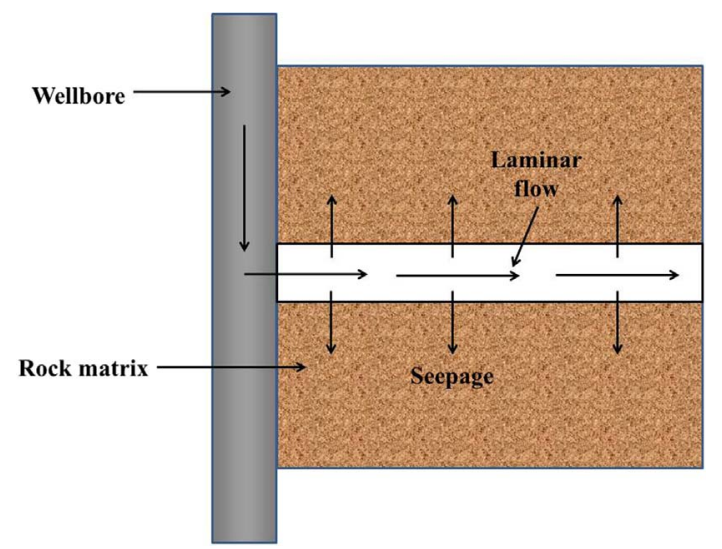

Fig. 3. Schematic diagram of drilling fluid loss in the rock matrix and fracture.

where $\emptyset_{\mathrm{f}}$ is the fracture porosity; $\rho$ is the drilling fluid density, $\mathrm{kg} / \mathrm{m}^{3} ; v_{\mathrm{f}}$ is the flow velocity in the fracture, $\mathrm{m} / \mathrm{s} ; q_{\mathrm{f}}$ is the seepage flow rate between fracture and rock matrix per unit rock volume in unit time, $\mathrm{kg} /\left(\mathrm{m}^{3} \mathrm{~s}\right) ; \emptyset_{\mathrm{m}}$ is the rock matrix porosity; $v_{\mathrm{m}}$ is the flow velocity in the rock matrix, $\mathrm{m} / \mathrm{s} ; q_{\mathrm{m}}$ is the seepage flow rate between fracture and rock matrix per unit rock volume in unit time, $\mathrm{kg} /\left(\mathrm{m}^{3} \mathrm{~s}\right)$.

In the passage, drilling fluid is incompressible and drilling fluid density is considered constant. Rock matrix is compressible, so $\emptyset_{\mathrm{m}}$ and $\emptyset_{\mathrm{f}}$ are not constant. $\emptyset_{\mathrm{m}}$ and $\emptyset_{\mathrm{f}}$ change with pressure. Derivation processes are as follows:

$$
\frac{\partial}{\partial t}\left(\emptyset_{\mathrm{m}} \rho\right)=\emptyset_{\mathrm{m}} \frac{\partial \rho}{\partial t}+\rho \frac{\partial \emptyset_{\mathrm{m}}}{\partial t}=0+\rho \frac{\partial \emptyset_{\mathrm{m}}}{\partial p} \frac{\partial P}{\partial t} .
$$

Based on the formula of rock compressibility, equation (5) can be expressed as:

$$
\frac{\partial}{\partial t}\left(\emptyset_{\mathrm{m}} \rho\right)=\emptyset_{\mathrm{m}} \frac{\partial \rho}{\partial t}+\rho \frac{\partial \emptyset_{\mathrm{m}}}{\partial t}=0+\rho C_{\mathrm{f}} \frac{\partial P}{\partial t},
$$

where $C_{\mathrm{f}}$ is the rock compressibility, $\mathrm{MPa}^{-1}$.

Fracture porosity can be expressed as follows:

$$
\emptyset_{\mathrm{f}}=\frac{2 w}{d},
$$


where $d$ is the distance between two parallel fractures, $\mathrm{m}$. It can be seen from the above formula, $\emptyset_{\mathrm{f}}$ changes with fracture width. Fracture width changes with pressure, so $\emptyset_{\mathrm{f}}$ changes with pressure too.

In the fracture, drilling fluid flow is laminar flow. For power-law fluid, fluid velocity in the fracture can be expressed as follows [24]:

$$
v_{\mathrm{f}}=\frac{n}{1+2 n}\left(\frac{w}{2}\right)^{\frac{1}{n}+1}\left(\frac{1}{K}\right)^{\frac{1}{n}}\left(\operatorname{grad}\left(P_{\mathrm{f}}\right)\right)^{\frac{1}{n}}
$$

where $P_{\mathrm{f}}$ is the pressure in the fracture, MPa.

In the rock matrix, drilling fluid flow follows Darcy law. For power-law fluid, fluid velocity in the rock matrix can be expressed as follows [25]:

$$
\begin{aligned}
v_{\mathrm{m}} & =\left(\frac{k_{\mathrm{m}}}{u_{\mathrm{eff}}}\right)^{\frac{1}{n}}\left(\operatorname{grad}\left(P_{\mathrm{m}}\right)\right)^{\frac{1}{n}}, \\
u_{\text {eff }} & =k_{\mathrm{m}}\left[\frac{k_{\mathrm{m}}}{12}\left(9+\frac{3}{n}\right)^{n}\left(150 k_{\mathrm{m}} \emptyset_{\mathrm{m}}\right)^{\frac{1-n}{2}}\right]^{n-1},
\end{aligned}
$$

where $u_{\text {eff }}$ is the effective viscosity, $\mathrm{mPa} \mathrm{s} ; P_{\mathrm{m}}$ is the formation pressure, $\mathrm{MPa} ; k_{\mathrm{m}}$ is the rock matrix permeability, $\mathrm{um}^{2}$.

At the beginning of drilling fluid loss, pressure in the fracture is same to the formation pressure. However, with the drilling fluid loss, pressure in the fracture increases and becomes larger than the formation pressure. At this moment, fluid seepage between fracture and rock matrix happens. The flow state can be regarded as steady flow. The crossflow rate can be expressed as follows:

$$
\left\{\begin{array}{l}
q_{\mathrm{f}}=a \rho \frac{d r}{2}\left[\frac{k_{\mathrm{m}}}{u_{\mathrm{eff}}} \frac{\left(P_{\mathrm{f}}-P_{\mathrm{m}}\right)}{\frac{d r}{2}}\right]^{\frac{1}{n}} \\
q_{\mathrm{m}}=-a \rho \frac{d r}{2}\left[\frac{k_{\mathrm{m}}}{u_{\mathrm{eff}}} \frac{\left(P_{\mathrm{f}}-P_{\mathrm{m}}\right)}{\frac{d r}{2}}\right]^{\frac{1}{n}},
\end{array}\right.
$$

where $a$ is the shape factor; $P_{\mathrm{m}}$ is the pore pressure, MPa; $d r$ is the length of grid in $x, y, z$ direction, $\mathrm{m}$.

The shape factor is expressed as follows [26, 27]:

$$
a=4\left(\frac{1}{L_{x}^{2}}+\frac{1}{L_{y}^{2}}+\frac{1}{L_{z}^{2}}\right),
$$

where $L_{x}, L_{y}, L_{z}$ are the length of the rock matrix in the $x, y, z$ direction, $\mathrm{m}$.

Substitute equations (5)-(11) into equation (3) and equation (4), the final equations are obtained.

\subsection{Drilling fluid flow rate and cumulative loss}

Wellbore is in the middle of the rectangle reservoir. Drilling fluid that losses from wellbore into formation mainly consists of two parts: a part of drilling fluid flows into formation through fractures that connect with the wellbore; the other part of drilling fluid leakages into formation through rock matrix. Equations of two different flow rates can be expressed separately as follows [28, 29]:

$$
\begin{gathered}
Q_{\mathrm{f}}=2 \pi h\left(\frac{n}{1+2 n}\right)\left(\frac{w}{2}\right)^{\frac{1}{n}+1}\left(\frac{1}{K}\right)^{\frac{1}{n}}\left[\frac{(n-1)\left(P_{w}-P_{f}\right)}{\left(r_{w}^{1-n}-r_{e}^{1-n}\right)}\right]^{\frac{1}{n}}, \\
Q_{\mathrm{m}}=2 \pi h\left[\frac{k(n-1)\left(P_{\mathrm{w}}-P_{\mathrm{m}}\right)}{u_{\mathrm{eff}}\left(r_{\mathrm{w}}^{1-n}-r_{\mathrm{e}}^{1-n}\right)}\right]^{\frac{1}{n}} .
\end{gathered}
$$

Cumulative volume of drilling fluid loss is obtained by integrating the flow rate in fractures and matrices over the time interval:

$$
V_{\text {cum }}=V_{\text {fcum }}+V_{\text {mcum }}=\int_{0}^{t_{\mathrm{f}}} Q_{\mathrm{f}}+\int_{0}^{t_{\mathrm{f}}} Q_{\mathrm{m}},
$$

where $Q_{\mathrm{f}}$ is the flow rate in the fracture, $\mathrm{m}^{3} / \mathrm{s} ; Q_{\mathrm{m}}$ is the flow rate in the rock matrix, $\mathrm{m}^{3} / \mathrm{s} ; V_{\text {fcum }}$ is the leakage volume in the fracture, $\mathrm{m}^{3} ; V_{\text {mcum }}$ is the leakage volume in the rock matrix, $\mathrm{m}^{3} ; V_{\text {cum }}$ is the drilling total leakage volume, $\mathrm{m}^{3} ; t_{\mathrm{f}}$ is the leakage time, $\mathrm{s} ; h$ is the formation height, $\mathrm{m}$.

\subsection{Initial and boundary conditions}

At the beginning of the leakage, pressure in the fracture is equal to the formation pressure. At the same depth, pressures are equal at anywhere [30]:

$$
P_{\mathrm{f}}=P_{\mathrm{m}}:(x, y) \subset\left(0<x<l_{x} \cap 0<y<l_{y}\right) .
$$

At the beginning, borehole pressure is large enough that the drilling fluid begins to leakage into fracture and rock matrix. Annular pressure drop in the leaking section can be ignored. From the beginning to the end, borehole pressure is constant:

$$
P=P_{w}: t>0 \text {. }
$$

Reservoir boundaries are considered impermeable, which are no-flow boundaries. Boundaries conditions can be expressed as follows:

$$
\left\{\begin{array}{l}
\frac{\partial P}{\partial x}=0:(x, y) \subset\left(x=0 \cap 0<y<l_{y}\right) \\
\frac{\partial P}{\partial x}=0:(x, y) \subset\left(x=l_{x} \cap 0<y<l_{y}\right) \\
\frac{\partial P}{\partial y}=0:(x, y) \subset\left(y=0 \cap 0<x<l_{x}\right) \\
\frac{\partial P}{\partial y}=0:(x, y) \subset\left(y=l_{y} \cap 0<x<l_{x}\right)
\end{array} .\right.
$$

\section{Mesh generation and stimulation}

In order to ensure the calculation speed and accuracy at the same time, graded meshing is used for meshing. The grids 


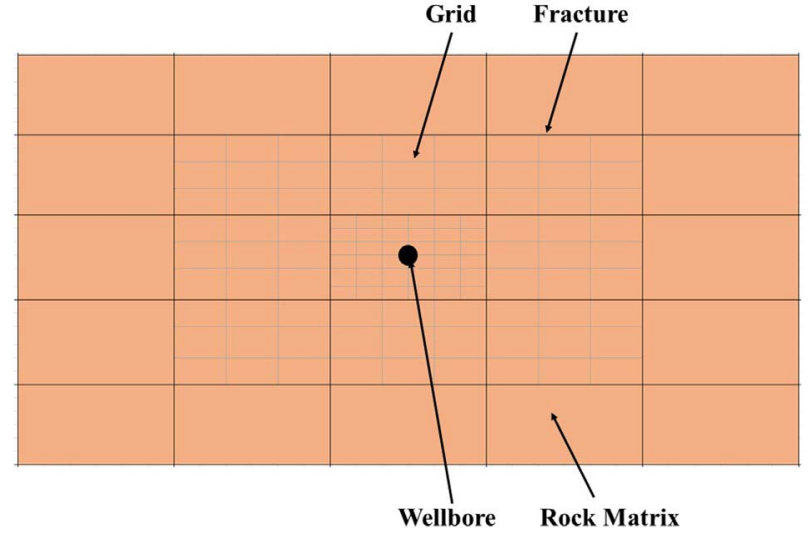

Fig. 4. Schemetic diagram of graded meshing.

are small near the wellbore in order to improve the precision, and the grids become large far away from the wellbore. The specific division method can be referred to Anderson [31] and Gilman and Kazemi [32]. The meshing diagram in the $x y$ plane is shown in Figure 4.

The finite difference method is used to solve the model. In order to reduce the calculation time, the full implicit scheme is used to differentiate the equations and form the algebraic equations to be solved. Because the equations are nonlinear, the Newton-Raphson method is used to solve the equations in this paper. In order to ensure the stability of calculation, a smaller time step should be chosen [33].

\section{Case study}

In order to validate the drilling fluid loss model, the numerical simulation is carried out by using the model in this paper. The parameters used in the simulation are listed in Table 1. At the same time, the influences of different parameters on the leakage are also analyzed.

\subsection{Influence of drilling fluid leak-off}

The drilling fluid leak-off refers to the drilling fluid seepage between fracture and rock matrix. As most of the previous studies did not take into account the permeability of the fracture wall, the drilling fluid leak-off effect was neglected. However, except for the special circumstance, the permeability of rock matrix is too large to be ignored. This is because that compared with the rock matrix pore volume, the fracture volume is too small. Pressure distributions in the fracture with and without considering the drilling fluid leak-off effect are illustrated in Figures 5 and 6 separately. It can be seen from the figures that pressure in the fracture increases faster without considering the influence of the drilling fluid leak-off. This is because that in the fracture-porosity reservoir, fracture mainly plays the role of transport channel rather than storage function. Compared with the rock matrix porosity volume, fracture volume is very small. If the effect of the drilling fluid leak-off is not considered, drilling fluid will be confined in the fracture and pressure
Table 1. Basic date for the calculation.

\begin{tabular}{lcc}
\hline Parameter name & Value & Unit \\
\hline Fracture length in $x$ direction & 20.0 & $\mathrm{~m}$ \\
Fracture length in $y$ direction & 20.0 & $\mathrm{~m}$ \\
Fracture length in $z$ direction & 20.0 & $\mathrm{~m}$ \\
Normal fracture stiffness & $5 \times 10^{10}$ & $\mathrm{~Pa} / \mathrm{m}$ \\
Initial fracture aperture & 0.1 & $\mathrm{~mm}$ \\
Formation porous & 0.1 & \\
Permeability & $50 \times 10^{-3}$ & $\mathrm{um}^{2}$ \\
Drilling fluid density & $1.2 \times 10^{3}$ & $\mathrm{~kg} / \mathrm{m}^{3}$ \\
Consistency index & 0.5 & $\mathrm{~Pa} \mathrm{~s}$ \\
Power law exponent & 0.5 & \\
Formation pressure & 50 & $\mathrm{MPa}$ \\
Borehole pressure & 45 & $\mathrm{MPa}$ \\
\hline
\end{tabular}

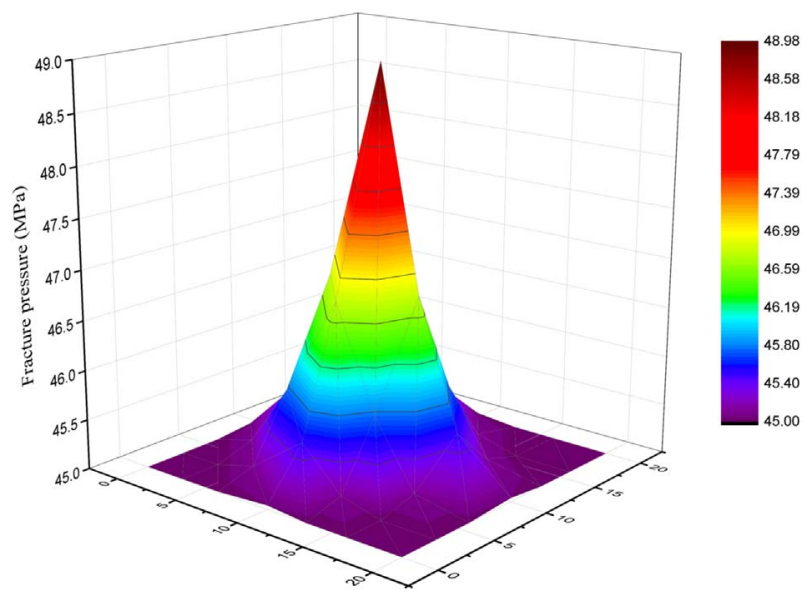

Fig. 5. Pressure distribution in the fracture considering leak-off at $t=600$.

in the fracture will rise rapidly. This is not in accordance with the fact.

The effect of the leak-off on the volume of drilling fluid is illustrated in Figure 7. It can be illustrated in Figure 7 that the plot of mud loss volume considering leak-off effect versus time almost produces a straight line. On the contrary, the curve of mud loss volume without considering leak-off effect becomes plat. When $t=600 \mathrm{~s}$, mud loss volume without considering leak-off effect is $0.097 \mathrm{~m}^{3}$, while mud loss volume considering leak-off effect is $0.26 \mathrm{~m}^{3}$. The difference between two values is large, so it is important to consider the leak-off effect when calculating the mud loss volume.

\subsection{Influence of the numbers of horizontal fractures}

The number of fractures is an important factor in the drilling fluid loss. More fractures mean more flow channels for the drilling fluid flow in the reservoir. In order to study 


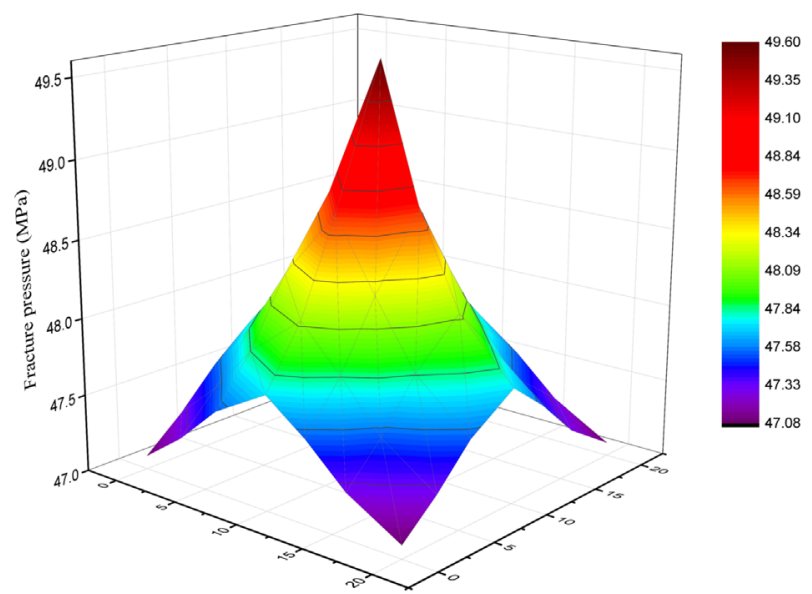

Fig. 6. Pressure distribution in the fracture without considering leak-off at $t=600$.

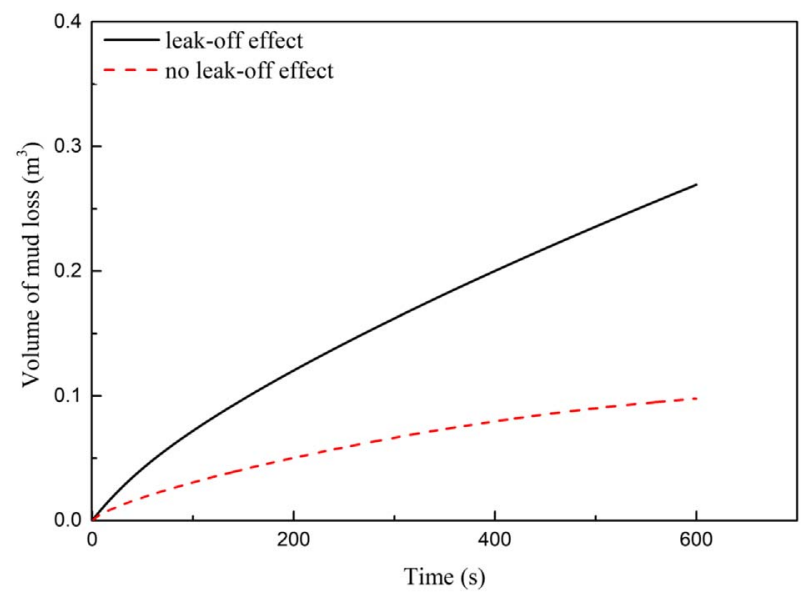

Fig. 7. Influence of the leak-off on mud loss volume.

the effect of the number of fractures, we have conducted simulation using three different numbers of horizontal fractures: $2,3,4$. Other input parameters are same to the values in Table 1. Figure 8 plots the calculated values of mud loss volume versus time. As Figure 8 shows, more horizontal fractures means more channels for drilling fluid flow from wellbore to the fracture. On the other hand, mud loss volume is not proportional to the number of fractures. Mud loss volume is $0.269 \mathrm{~m}^{3}$ when the number of fractures is 2, while it is $0.406 \mathrm{~m}^{3}$ when the number of fractures is 4 . This is because of the influence of rock matrix. Under the situation of more fractures, pore pressure increases faster, which will make the seepage between fracture and rock matrix slow.

\subsection{Influence of normal fracture stiffness}

The normal fracture stiffness mainly influences the fracture width, as explained in equation (1). The larger the normal fracture stiffness is, the harder the rock is and more difficult to be compressed. Variation of fracture width will influence

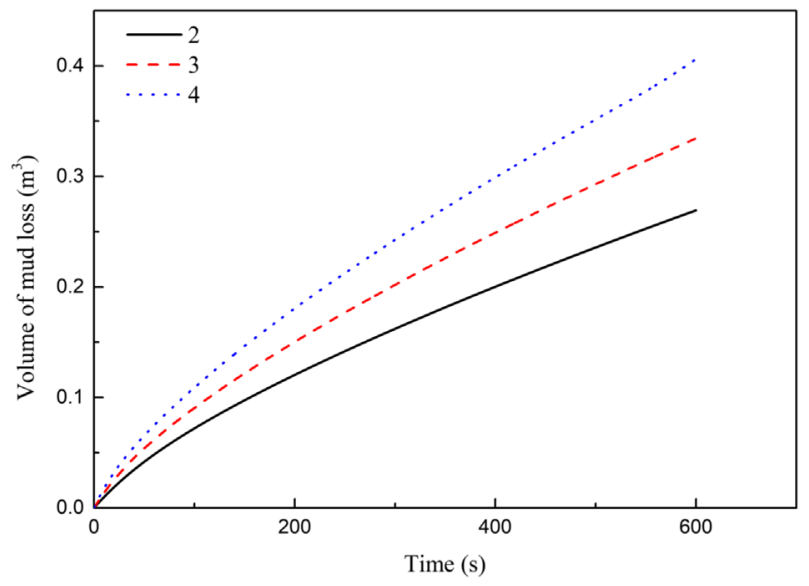

Fig. 8. Influence of the number of fractures on the mud loss volume.

the fracture volume and the permeability of fracture. In order to study the effect of the normal fracture stiffness, mud loss volumes under different normal fracture stiffness are calculated. The fracture stiffness are $5 \times 10^{10}, 10^{11}$, $5 \times 10^{11} \mathrm{~Pa} / \mathrm{m}$, respectively. Other input parameters are same to the values in Table 1 . The result is illustrated in Figure 9. When drilling fluid begins to seep into fracture, pressure in the fracture increases. If the fracture stiffness is smaller, the rock matrix is easier to compress, which results in wider flow channel under the same pressure difference and higher mud loss rate. As fracture stiffness increases from $5 \times 10^{10} \mathrm{~Pa} / \mathrm{m}$ to $5 \times 10^{11} \mathrm{~Pa} / \mathrm{m}$, mud loss volume decreases from $0.269 \mathrm{~m}^{3}$ to $0.042 \mathrm{~m}^{3}$, which indicates that fracture stiffness has great influence on the mud loss volume.

\subsection{Influence of pressure difference}

Pressure difference indicates the pressure difference between wellbore pressure and fracture pressure. According to the equations (10) and (11), pressure difference has direct influence on the drilling fluid flow rate in the fracture. On the other hand, the value of pressure difference has no influence on the storage space both in the fracture and rock matrix. In order to study the influence of the pressure difference, mud loss volumes under different pressure difference are calculated. The pressure differences are 2, 5, $8 \mathrm{MPa}$ respectively. Other input parameters are same to the values in Table 1. The result is illustrated in Figure 10. Pressure difference between wellbore pressure and fracture pressure is the main power source that pushes drilling fluid flowing forward in the fracture, so it has direct influence on the mud loss rate. Just as Figure 10 shows, the larger the pressure difference is, the faster the mud loss volume increases. Compared with other factors, pressure difference has the great influence.

\subsection{Influence of rock matrix porosity}

In the fracture-porosity reservoir, rock matrix porosity is the main storage space. The larger the rock matrix porosity 


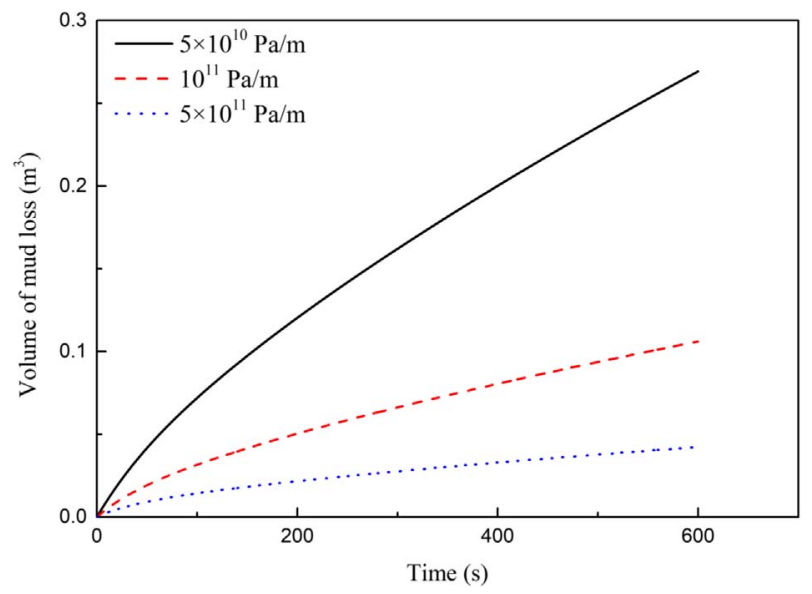

Fig. 9. Influence of the normal stiffness of the fracture on the mud loss volume 1 .

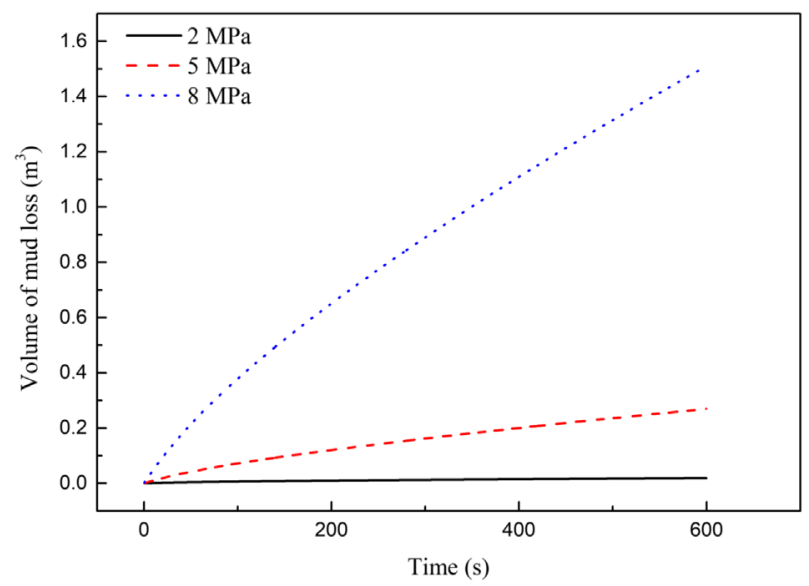

Fig. 10. Influence of the pressure difference on the mud loss volume.

is, the slower the pore pressure increases and drilling fluid seepage between fracture and rock matrix decreases. In order to study the effect of the rock matrix porosity, mud loss volumes under different rock matrix porosities are calculated. The rock matrix porosities are $10 \%, 20 \%$, $30 \%$ respectively. Other input parameters are same to the values in Table 1 . The influence of the rock matrix porosity on the mud loss volume is illustrated in Figure 11. As Figure 11 shows, rock matrix porosity does not have great influence on the drilling fluid volume increase rate. Under different rock matrix porosities, the trends of the curves of the mud loss volume are similar, only the slopes of the curve are a little different. This is because rock matrix is not the drilling fluid flow channel, the value of rock matrix porosity can not directly influence the drilling fluid flow rate in the fracture. It can only indirectly influence the drilling fluid loss rate by influencing the leak rate between fracture and rock matrix.

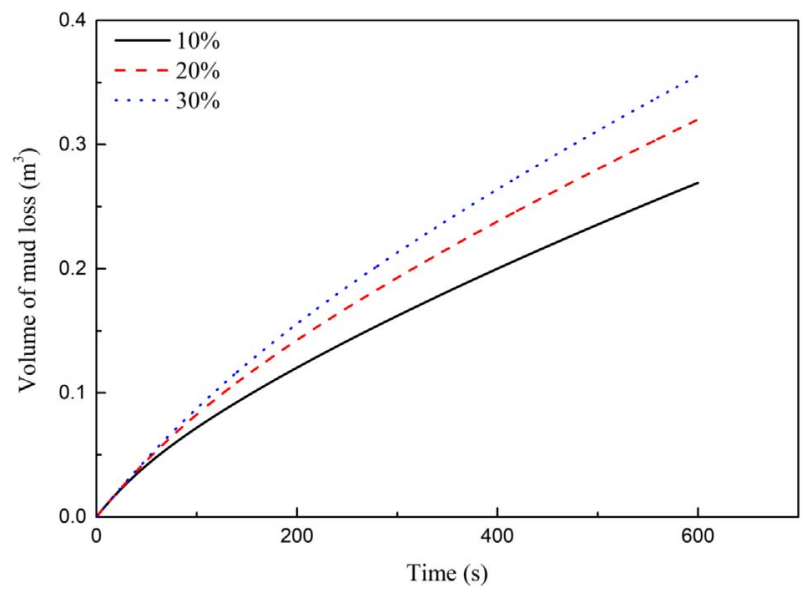

Fig. 11. Influence of the rock matrix porosity on the mud loss volume.

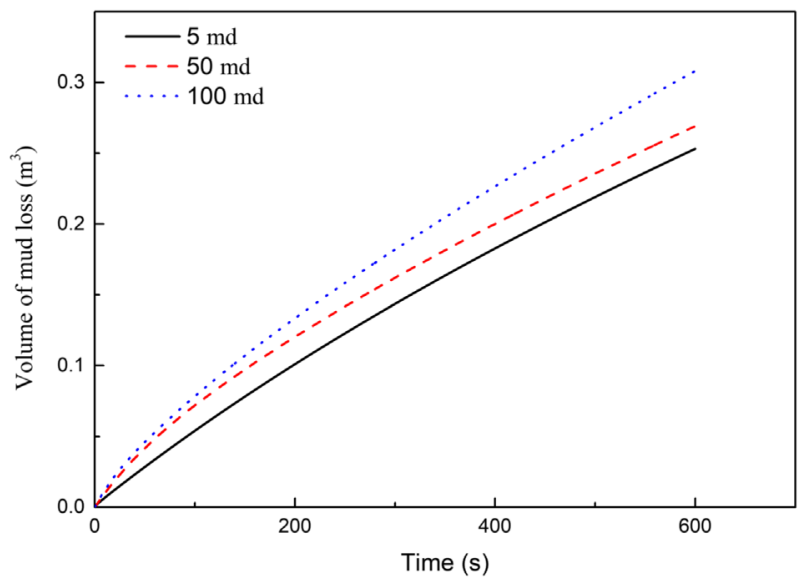

Fig. 12. Influence of the rock matrix permeability on the mud loss volume.

\subsection{Influence of rock matrix permeability}

Permeability is another important property of rock matrix. It mainly influences the seepage velocity of drilling fluid in the rock matrix and between fracture and rock matrix. In order to study the effect of the rock matrix permeability, mud loss volumes under different rock matrix permeabilities are calculated. The rock matrix permeabilities are 5, 50, 100 md respectively. Other input parameters are same to the values in Table 1 . The effect of rock matrix permeability on the mud loss volume is illustrated in Figure 12. As Figure 12 shows, similar to the effect of rock matrix porosity, the rock matrix permeability does not have great influence on the drilling fluid volume increase rate. Under different rock matrix permeabilities, the trends of the curves of the mud loss volume are similar, only the slopes of the curve are a little different. This is because rock permeability can only indirectly influence the drilling fluid loss rate by 
influencing the seepage velocity of drilling fluid in the rock matrix and between fracture and rock matrix. Compared with the flow velocity in the fracture, seepage velocity is small. Although permeability is raised 20 times, mud loss volume only increases 0.2 times.

\section{Conclusion}

Based on the dual-medium theory, a mathematical model for drilling fluid loss in fracture-porosity formation has been developed. Drilling fluid flow in the fracture and drilling fluid seepage between fracture and rock matrix are both described in the model. Several simulations were conducted to examine the influence of several parameters on the drilling mud loss. Numerical simulation with the model has shown that:

1. Drilling fluid leak-off has great influence on the mud loss volume. Leak-off results in a faster mud loss rate and larger mud loss volume. It will make great error if leak-off is ignored.

2. As the main channel of drilling fluid flow, the number of fractures has positive influence on the drilling fluid loss. The more fractures, the faster the drilling fluid loss rate is.

3. Compared with other influencing factors, pressure difference between wellbore and fracture has dominate influence on the drilling fluid loss. The larger the pressure difference is, the faster the drilling fluid loss rate is.

4. Fracture stiffness has negative influence on the drilling fluid loss. The larger the fracture stiffness is, the smaller the fracture width is, the slower the drilling fluid loss rate is.

5. The larger the porosity or permeability is, the faster the drilling fluid loss rate is. But compared with influence of fracture, rock matrix has limited influence on the drilling fluid loss.

\section{References}

1 Jin Y., Chen M. (2007) Statistic analysis of leakage pressure of Ordovician carbonate formation in middle Ttarim basin, ODPT 29, 5, 82-84. https://doi.org/10.1016/S1872-5813 (07)60034-6 (in Chinese).

2 Wang W.B., Ma T.H., Deng T. (2005) Characteristics and geological factors of vicious Lost circulation in XuanhanKaijiang area of east Sichuan, Nat. Gas Ind. 25, 2, 90-92. https://doi.org/10.1016/j.molcatb.2005.02.001 (in Chinese).

3 Lietard O., Unwin T., Guillot D., Hodder M. (1996) Fracture width LWD and drilling mud/LCM selection guidelines in naturally fractured reservoirs, in: Paper presented at European Petroleum Conference, 22-24 October, Milan, Italy. https://doi.org/10.2523/36832-MS.

4 Sanfillippo F., Brignoli M., Santarelli F.J. (1997) Characterzation of conductive fractures while drilling, in: Paper presented at SPE European Formation Damage Conference, The Hague, The Netherlands. https://doi.org/10.2118/38177-MS.
5 Verga F.M., Carugo C., Chelini V., Maglione R., Bacco G.D. (2000) Detection and characterization of fractures in naturally fractured reservoirs, in: Paper presented at SPE Annual Technology Conference and Exhibition, 1-4 October, Dallas, Texas. https://doi.org.10.2118/63266-MS.

6 Lavrov A., Tronvoll J. (2003) Mud loss into a single fracture during drilling of petroleum wells: modeling approach, in: Paper presented at the 6th International Conference on Analysis of Discontinuous Deformation, 5-8 October, Trondheim, Norway.

7 Lavrov A., Tronvoll J. (2004) Modeling mud loss in fractured formations, in: Paper presented at Abu Dhabi International Conference and Exhibition, 10-13 October, Abu Dhabi, United Arab Emirates. https://doi.org/10.2523/ 88700-MS.

8 Tempone P., Lavrov A. (2008) DEM modeling of mud losses into single fractures and fracture network, in: Paper presented at the 12th International Conference of International Association for Computer Methods and Advances in Geomechanics, 10-13 October, Abu Dhabi, United Arab Emirates. https://doi.org/10.2523/88700-MS.

9 Majidi R., Miska S.Z., Yu M., Thompson L.G. (2008) Fracture ballooning in naturally fractured formations: mechanism and controlling factors, in: Paper presented at SPE Annual Technical Conference and Exhibition, 21-24 September, Denver, CO, USA. https://doi.org10.2118/115526-MS.

10 Majidi R., Miska S., Thompson L.G., Yu M., Zhang J.G. (2010) Quantitative analysis of mud losses in naturally fractured reservoirs: the effect of rheology, SPE Drill. Completion 25, 4, 509-517. https://doi.org/10.2118/114130-PA.

11 Ozdemirtas M., Babadagli Y., Kuru E. (2009) Experimental and numerical investigations of borehole ballooning in rough fractures, SPE Drill. Completion 24, 2, 256-265. https://doi. org/10.2118/110121-PA.

12 Li D.Q., Kang Y.L., Liu X.S., Zeng Y.J., Du C.C. (2011) The lost circulation pressure of carbonate formations on the basis of leakage mechanisms, Acta Petrol. Sinica 32, 5, 900-904. https://doi.org/10.7623/syxb201105026 (in Chinese).

13 Razavi O., Lee H.P., Olson J.E., Schultz R.A. (2017) Drilling mud loss in naturally fractured reservoirs: theoretical modeling and field data analysis, in: Paper presented at SPE Annual Technology Conference and Exhibition, 9-11 October, San Antonio, TX, USA. https://doi.org/10.2118/187265-MS.

14 Wang Z.Y., Sun B.J., Ke K. (2014) Pre-Spud mud loss flow rate in steeply folded structures, Oil Gas Sci. Technol. - Rev. IFP Energies nouvelles 69, 7, 1269-1281. https://doi.org/ $10.2516 /$ ogst $/ 2012105$.

15 Xia Y., Jin Y., Chen M., Chen K.P., Lin B.T., Hou B. (2015) Hydrodynamic modeling of mud loss controlled by the coupling of discrete fracture and matrix, J. Pet. Sci. Eng. 129, 254-267. https://doi.org/10.1016/j.petrol.2014.07.026.

16 Xia Y., Jin Y., Wei S.M., Zhang Y.Y., Xiang J.H., Zhong H. (2018) Characterization of multi-scale discrete-fracture/ matrix interactions in naturally fractured reservoirs using mud loss data, in: Paper presented at the 2nd International Discrete Fracture Network Engineering Conference, 20-22 June, Seattle, WA, USA.

17 Warren J.E., Root P.J. (1963) The behavior of naturally fractured reservoirs, Soc. Pet. Eng. J. 3, 3, 245-255. https://doi.org/10.2118/426-PA.

18 Jia L.C., Chen M., Hou B., Sun Z., Jin Y. (2014) Drilling fluid loss model and loss dynamic behavior in fractured formations, Petrol. Explor. Develop. 41, 1, 105-112. https://doi.org/10.1016/S1876-3804(14)60012-4. 
19 Bruel D., Cacas M.C., Ledoux E., Marsily G.D. (1994) Modelling storage behaviour in a fractured rock mass, J. Hydrol. 162, 3-4, 267-278. https://doi.org/10.1016/ 0022-1694(94)90231-3.

20 Hemphill T., Campos W., Pilehvari A. (1993) Yield-power law model more accurately predicts mud rheology, Oil Gas J. 91, 34, 45-50.

21 Robertsion R.E., Stiff H.A. (1976) An improved mathematical model for relating shear stress to shear rate in drilling fluids and cement slurries, SPE J. 16, 1, 31-36. https://doi. org/https://doi.org/10.2118/5333-PA.

22 Peng X.L., Du Z.M., Liang B.S., Qi Z.L. (2009) Darcy-stokes streamline simulation for the Tahe-fractured reservoir with cavities, SPE J. 14, 3, 543-552. https://doi.org/10.2118/ 107314-PA.

23 Réthoré J., Borst R.D., Abellan M.A. (2007) A two-scale approach for fluid flow in fractured porous media, Int. J. Numer. Meth. Eng. 71, 7, 780-800. https://doi.org/10.1002/ nme.1962.

24 Cheng L.S. (2011) Advanced mechanics of fluids in porous media, 1st edn., Petroleum Industry Press, Beijing, pp. 243-261.

25 Williams B.B. (1990) Fluid loss from hydraulically induced fractures, J. Pet. Technol. 22, 7, 882-888. https://doi.org/ 10.2118/2769-PA.

26 Kazemi H. (1969) Pressure transient analysis of naturally fractured reservoirs with uniform fracture distribution, Soc. Pet. Eng. J. 9, 4, 451-462. https://doi.org/10.2118/2156-A.
27 Kazemi H., Merrill L.S., Porterfield K.L., Zeman P.R. (1976) Numerical simulation of water-oil flow in naturally fractured reservoirs, SPE J. 16, 6, 1114-1122. https://doi.org/ 10.2118/5719-PA.

28 Fanchi J.R. (2006) Principles of applied reservoir simulation, 3rd edn., Elsevier Inc. USA, pp. 27-50.

29 Ge J.L. (1998) Nonlinear fluid mechanics of complex influent system, 1st edn., China University of Petroleum Press, Dongying, pp. 58-66.

30 Shahri M.P., Mehrabi M. (2012) A new approach in modeling of fracture ballooning in naturally fractured reservoirs, in: Paper presented at SPE Kuwait International Petroleum Conference and Exhibition, 10-12 December, Kuwait City, Kuwait. https://doi.org/10.2118/163382-MS.

31 Anderson J.D. (1995) Computational fluid dynamics, 1st edn., McGraw-Hill Science, USA, pp. 116-148.

32 Gilman J.R., Kazemi H. (1982) Improvements in simulation of naturally fractured reservoirs, Soc. Pet. Eng. J. 23, 4, 695-707. https://doi.org/10.2118/10511-PA.

33 Clifton R.J., Abou-Sayed A.S. (1979) On the computation Of the three-dimensional geometry of hydraulic fractures, in: Paper presented at the Symposium on Low Permeability Gas Reservoirs, 20-22 May, Denver, CO, USA. https://doi.org/ $10.2118 / 7943-\mathrm{MS}$. 